\section{A perspective on aging}

As medical advances pursue their seemingly unstoppable course, as measured by the steady increase of life expectancy, it was greatly hoped that this increase would be matched by a compression of morbidity; in other words people would live lives both longer and healthier. Instead, there has been a perplexing expansion of morbidity [9]the interval of healthy life has not much increased, and it is now followed, for an increasing number of people, by a long interval of poor, even debilitatingly so, health. While world population continues to increase, there is a disproportionate increase in the number of aged people. In the developed world, most countries have sophisticated healthcare systems in place, and this expansion of morbidity has led to an enormous, possibly unsustainable, increase in healthcare costs (in England, about $40 \%$ of the budget of the National Health Service is spent on those over 65 years old). Some authors have proposed drastic remedies, such as severely constraining healthcare expenditure on subjects more than 80 years old [1] Whether that is acceptable is, ultimately, an ethical question, of which more presently.

The recent general election campaign in the United Kingdom threw up a number of key issues on this very topic, most notably the financing of care for the elderly. In the UK, as in many European countries, people of advanced age who, because of infirmity, need to be looked after more intensively than can be done by members of their family, or who have no family, may be cared for by the State. When the National Health Service Bill was introduced in 1946, mean life expectancy was not much greater than the age at which people customarily retired from work and no special provision for care was made. Seventy years later we have a very different situation. Life expectancy has increased by almost two decades but has been accompanied by an expansion of morbidity and, for many people, the last decade or so of life may be one of considerable dependency on other people for survival; the trend towards smaller families means that in many cases these "other people" are professional carers who must be paid.1, 2 The growing proportion of elderly people, coupled with the expansion of morbidity and the parlous condition of State finances means that the present régime is becoming unaffordable. Particularly problematical is the fact that there has been a significant increase in the number of people suffering from dementia; advances in medicine often ensure that such people are physiologically well but unable to look after themselves. At present, about $10 \%$ of people being cared for end up paying over 100,000 GBP for care. This is considered to be in some way "unfair"; the popular press has called it a "dementia tax" and written about a "dementia lottery", amplifying the apparently widely held idea that the occurrence of dementia is a random event unrelated to decisions made earlier in life regarding diet, physical exercise, mental exertion and so forth. An important motivation of the critics seems to be the cupidity of descendants and other relatives, who wish to preserve as much as possible of the invalid's estate for their own use. There is no defensible moral sanction for this, nor is there compelling evidence that dementia is not the result of actions taken earlier in life by adults in a state of full moral responsibility. Nevertheless, responding to popular pressure, the previous government proposed imposing a cap of 72,000 GBP on care costs, but this was changed in the Conservative Party election manifesto to expenditure limited only by an irreducible residue of 100,000 GBP's worth of assets. Even this is not really morally defensible, but the thought that invalids would be rendered destitute by the cost of care triggered outrage among people who saw their potential inheritance evaporating, and the Party responded by promising to reintroduce the idea of a cap, although the amount was not specified; at that point in the campaign sensible arithmetic regarding public income and expenditure was no longer being attempted by any party.

Although Manini et al. [6] have written about the "staggering economic, public and personal burden" of age-related muscle weakness, this is, perhaps, a somewhat stereotyped exaggeration. As humans age, undoubtedly neuromuscular weakening takes place, albeit via complex mechanisms that at present are little understood [14], although the social implications of the phenomenon are well appreciated. Around Christmas time in Switzerland one can find the ancient proverb "Die Alten zum Rat, die Jungen zur Tat" embossed on Tirggel, a traditional honey cookie from Zürich. Nevertheless, in modern times, the State or employer or

\footnotetext{
1 Under existing arrangements in the UK, if the infirm person moves to a care home, the costs will be paid for by the State (usually the local authority) if they exceed 23,250 GBP. ${ }^{2}$ Home help is also subsidized according to means (excluding the value of the patient's home).

2 According to the Alzheimer's Society, the average annual cost of looking after a person with dementia is 32,250 GBP.
} 
both pay a pension to employees upon reaching a certain fixed age, beyond which they are no longer obliged to to work (and in some cases obliged to retire). ${ }^{3}$ Illogically, no distinction is made between workers using brawn (who might well be fatigued at age 50 or brain (who might be able to carry on indefinitely). ${ }^{4,5}$ Physiological and other changes occurring with age have attracted a good deal of interest in recent years. Wang et al. point out that "executive and working memory functions decline early in the normal aging process" [15] —obviously a generalization that does not apply to everyone. Mattson and Magnus [7] and others consider that neural degeneration might be solely due to disease, rather than an inevitable result of genetic programming (cf. Rutten et al. [10]). Morrison and Hof [8] had already noted that functional impairment in aging is very different from impairment due to disease. The old idea that there is general an inevitable decline in neuron number with age is not really justified by the evidence (e.g., "neuron death is not significantly involved in normal aging" [8]); the notion dates back to a time when neuron counting abilities were more primitive than nowadays $[2,3] .{ }^{6}$ Soreq et al. point out that "human brain aging is determined by a complex interplay of regional and cell-type-specific molecular events" [12].

The implication of "Die Alten zum Rat, die Jungen zur Tat" is that work requiring physical energy, such as soldiering, any kind of manual labour, laboratory bench work and the like, should be carried out by the young, whereas advisory work, such as planning, legislation and the like, should be carried out by the old. The proverb is predicated on the idea of muscular, but not mental, weakening in old age; as with most proverbs, it reflects things as they are, or perceived to be. In fact, recent research, especially at the level of molecules and cells, is tending to reveal that degeneration of neurons controlling muscles could be a significant contributor to apparently weakening muscles [6]. Conversely, there seems to be growing evidence that physical fitness preserves and promotes brain health. Besides, productive tasks requiring intensive mental activity are surely included within the umbrella of deeds, die Tat. Advice, der Rat, benefits from accumulated experience, perhaps more so than actively productive tasks.

Examining what happens at the cellular level is, however, unlikely to yield a complete picture. Changing desires of how to live one's life as it progresses are due to innumerable factors, many of them in one's environment. Inevitably, one's circle of friends, typically formed in youth, diminishes with time; lack of socializing is perceived as a major cause of health problems in the elderly [11]. This problem appears to be particularly acute in what are considered to be the most advanced countries; in contrast, in a country like Azerbaijan, the tradition of many generations living together persists, with concomitant benefits for both individual and society. By actively recruiting the elderly for all the advisory rôles needed in modern society (including membership of local councils, Parliament and the innumerable quangos), the problem of a dearth of opportunities to socialize would be greatly diminished. A further advantage is that older people tend to be less actively engaged in money-making activities and should,

3 At age 70 when the State pension was first introduced in the UK in 1908 (when average life expectancy was a little under 50 years). The scheme was and is non-contributory (i.e., paid out of general taxation). France has similar arrangements from age 60 ; in Switzerland from age 65. Compulsory retirement age was abolished in the UK in 2011. Private schemes were already in existence (e.g., for staff of the railway companies, from the mid-19th century onwards). Antecedents can be found centuries earlier, such as the Chatham Chest for disabled seamen (1590). Those in government service (the Royal Navy), or working for firms closely associated with the government, such as the East India Company and the Bank of England, benefited from schemes set up in the late 17th century and onwards. A friendly society for the printers of Oxford University was set up in 1707. By 1810 the entire civil service benefited from a superannuation fund. In parallel, provision was made for indigence, whether caused by lack of ability or age, starting with the Poor Law of 1601 (amended in 1834 in order to deter indolence).

4 Unless, that is, some specific brain disease occurs, such as Alzheimer's or dementia. Otherwise, there is little evidence that brain function declines with age; on the contrary, there are many examples of artists, engineers, scientists and others whose work increased in brilliance as they got older. I have personally met, and played with, at least two (nonprofessional) tennis players of great age, who explained to me that they were able to compensate for neuromuscular weakening by placing shots more cleverly, thanks to experience, and hence often able to win against much younger players. Only in mathematics does one have a clearer impression that inventiveness of thought declines with age, but the evidence is not wholly convincing, not least because some brilliant mathematicians (e.g., Galois) died very young and there are counterexamples of mathematical geniuses continuing to work with undiminished or even increasing (because of the accumulation of experience) powers until their death (e.g., Euler). ${ }^{5}$ It is extremely difficult to take all possible confounding factors into account as life progresses. Many events in life not directly related to one's professional activity may influence, positively or negatively, the quality and quantity of one's work.

5 One notices a similar trend among musicians - while some died young, seemingly in the flower of their brilliance (e.g., Schubert) others lived a normal lifespan seemingly ever more productively (e.g., Johann Sebastian Bach, whose last work, Die Kunst der Fuge, may be the most brilliant musical composition of all time).

6 See Morrison and Hof [8] for more discussion on this point. 
therefore, have no vested interest in one decision outcome over another, and hence can judge each matter purely on its merits.

The starting point of this essay was the unsustainability of burgeoning healthcare costs, largely due to the growing size of the aged cohort in need of care to survive. Even if economic growth delivers the material means to provide that care [13], it does not seem right socially for a large and growing proportion of the population to be effectively switched out of society.

If the problem were purely one of frailty, there is much useful work to be done of an advisory nature-legislative councils and the like. The advantages of confiding these kinds of jobs to the elderly have already been pointed out, to which we might add the unburdening of younger people from these administrative kinds of duties, which they typically find intolerably tedious. The problem with dementia is that it effectively removes people from every kind of activity, both mental and physical.

At the present time, the causes of dementia are not understood sufficiently well to enable the disease to be evaded or cured. Nevertheless, it does seem as though continuous meaningful social engagement is very important for delaying the onset of dementia, possibly indefinitely. Filling advisory, legislative etc. bodies with the elderly, who would thereby have real work to do, could, therefore, fulfil a vital medical function. Furthermore, the unburdening would free up the time of younger relatives of the elderly to spend more social time with them, adding to or multiplying the benefit.

Other possible activities include rescuing Wikipedia from decline by thoroughly and impartially revising and carefully rewriting articles, free from the muddle, bias and political agendas that seem to pervade so many of the pages; and managing investment portfolios, requiring painstaking investigations of companies whose shares might be bought or sold.

To be sure, sitting on legislative councils will not be to everyone's liking. There are plenty of alternatives. The steady growth of scientific work opens up new areas of research faster than they can be tackled. The elderly could also offer their time as research assistants to active scientists, helping with data analysis and literature searches and a host of other similar kinds of work such as compiling indexes and glossaries. Thanks to the Internet, most of this work could be carried out within the existing framework of care homes. Once these new activities are under way, any visitor should be struck by the buzz upon entering the building. Given, too, likely rôle of exposure to noise (in the general sense of tumultuous activity) maintaining a healthy brain [5, 4], living in an everyday environment with plentiful noise will be a collateral benefit.

\section{J.J. RAMSDEN}

\section{References}

1. Callahan, D. Medical progress and global chronic disease: The need for a new model. Brown J. World Affairs 20 (2013) 35-46.

2. Clarke, P.G.H. and Cowan, W.M. The development of the isthmo-optic tract in the chick, with special reference to the occurrence and correction of developmental errors in the location and connections of isthmo-optic neurons. $J$. Comp. Neurol. 167 (1976) 143-164.

3. Clarke, P.G.H., Rogers, L.A. and Cowan, W.M. The time of origin and the pattern of survival of neurons in the isthmooptic nucleus of the chick. J. Comp. Neurol. 167 (1976) $125-142$

4. Clarke, P.G.H. The limits of brain determinacy. Proc R. Soc. B 279 (2012) 1665-1674.

5. Erdi, P. and Barna, Gy. Self-organizing mechanism for the formation of ordered neural mappings. Biol. Cybernetics $\mathbf{5 1}$ (1984) 93-101.

6. Manini, T.M., Hong, S.L. and Clark, B.C. Aging and muscle: a neurons perspective. Current Opinion Clin. Nutr. Metab. Care 16 (2013) 21-26.

7. Mattson, M.P. and Magnus, T. Aging and neuronal vulnerability. Nature Rev. Neurosci. 7 (2006) 278-294.

8. Morrison, J.H. and Hof, P.R. Life and death of neurons in the aging brain. Science 278 (1997) 412-419.

9. Olshansky, S.J. et al. Trading off longer life for worsening health: the expansion of morbidity hypothesis. J. Aging Health 3 (1991) 194-216.

10.Rutten, B.P.F. et al. The aging brain: Accumulation of DNA damage neuron loss? Neurobiol. Aging 28 (2007) 91-98.

11.Singh, A. and Misra, N. Loneliness, depression and sociability in old age. Ind. Psychiatry J. 18 (2009) 51-55.

12.Soreq, L. et al. Major shifts in glial regional identity are a transcriptional hallmark of human brain aging. Cell Rep. 18 (2017) 557-570.

13. Thomas, P. Does health spending need to outpace GDP per head? Nanotechnol. Perceptions 13 (2017) 17-30.

14. Vandervoort, A.A. Aging of the human neuromuscular system. Muscle Nerve 25 (2002) 17-25.

15.Wang, M. et al. Neuronal basis of age-related working memory decline. Nature 476 (2011) 210-213. 